\title{
Characterization of a New Natural Periclinal Navel-Satsuma Chimera of Citrus: 'Zaohong' Navel Orange
}

\author{
Min Zhang, Xiuxin Deng', Changping Qin, Chunli Chen, Hongyan Zhang, Qing Liu, \\ Zhiyong Hu, and Linlin Guo \\ National Key Laboratory of Crop Genetic Improvement, National Center of Citrus Breeding, \\ Huazhong Agricultural University, Wuhan 430070, China
}

\author{
Wenhua Song, Yong Tan, and Shengcai Liao \\ Zigui Agricultural Bureau, Zigui County, Hubei Province, 443600 China
}

\begin{abstract}
Additional INDEX words. graft chimera, flow cytometry, HPLC, carotenoid, SSR, cpSSR
Abstract. 'Zaohong' navel orange [Citrus sinensis (L.) Osbeck + C. unshiu Marc.], a new strain of citrus from a graft chimera, was discovered in China. It was diploid and arose at the junction where a 'Robertson' navel orange scion was top-worked onto a Satsuma mandarin $\left(C\right.$. unshiu). Some characteristics determined by the $\mathrm{L}_{1}$ cell layer, such as juice sacs of fruit and stoma length, were similar to those of Satsuma mandarin, while others, including leaf index, fruit shape, navel, and color and aroma of the rind, were determined by the $L_{2}$ cell layer, were similar to 'Robertson' navel orange. High-performance liquid chromatography analysis of the carotenoid extracts of the flesh of 'Zaohong' navel orange indicated that it had the carotenoids profile of Satsuma mandarin with $\beta$-cryptoxanthin as the predominant component in the juice sacs in mature fruit. Simple sequence repeats (SSR) and chloroplast simple sequence repeats (cpSSR) analysis showed that both nuclear and chloroplast genomes of 'Zaohong' navel orange were composed of both donor plants. On the basis of these facts, 'Zaohong' navel orange was found to be a periclinal chimera consisting of $L_{1}$ derived from Satsuma mandarin and $L_{2} / L_{3}$ from 'Robertson' navel orange. It combined the valuable traits of both donor plants, matured $\approx 1$ month earlier than the present navel orange cultivars, and therefore had good potential in citrus fresh market.
\end{abstract}

Citrus is an economically important fruit crop grown in tropical and subtropical climates in a large number of countries. Because of heterozygosity, polyembryony, male or/and female abortion, and long juvenility, most important citrus scion cultivars were from bud mutation instead of cross breeding (Asins et al., 1999; Spiegel-Roy and Goldschmidt, 1996). Mutations arise often in citrus and are generally detected by the growers themselves in branches of trees showing altered horticultural traits, such as maturity and flowering time or fruit characteristics.

Schmidt (1924) presented the "tunica-corpus" concept to describe the stratified appearance of the cell layers in the shoot apical meristems of flowering plants. Most dicots have three distinct apical cell layers $\left(\mathrm{L}_{1}, \mathrm{~L}_{2}\right.$, and $\left.\mathrm{L}_{3}\right)$ that remain independent from each other, while monocots commonly have two- or three-layered apices (Burge et al., 2002; Doring et al., 1999). In citrus fruit, both the juice sac and pericarp epidermis originate from $\mathrm{L}_{1} ; \mathrm{L}_{2}$ ordinarily produces seeds, segment walls, the hypoderm, and the mesocarp of pericarp; while $\mathrm{L}_{3}$ develops into the vascular bundle (Frost and Krug, 1942; Sugawara et al., 1995).

Received for publication 26 July 2006. Accepted for publication 27 Jan. 2007. This work was supported by the NSFC (30471201), the National 863 Project, the Ministry of Education (IRT0548), and the Department of Science \& Technology of Hubei Province.

The authors are grateful to Dr. Guo Wenwu, Liu Jihong, and M.K. Biswas for their critical readings of the manuscript.

${ }^{1}$ Corresponding author. E-mail: xxdeng@mail.hzau.edu.cn.
According to the "tunica-corpus" theory, a plant chimera is a mosaic in which genetically different cells exist in the shoot apical meristem that gives rise to cells that develop into organs of the plant. Graft chimeras arisen spontaneously or by artificial synthesis have been reported previously, such as 'Kobayashi Mikan' (C. unshiu + C. natsudaidai Hayata) (Tanaka, 1980), 'Kinkoji Unshiu' (C. unshiu + C. obovoidea Takahashi) (Tanaka, 1980), 'Gouheju' (C. reticulata Blanco + C. aurantium Linn.) (Shen et al., 1998), and 'Hongjiangcheng' (C. sinensis + C. reticulata) (Shen et al., 1998). An intergeneric grafting chimera named 'Zhihelu' [C. reticulata + Poncirus trifoliate (L.) Raf.] between 'Ponkan' (C. reticulata) and trifoliate orange (P. trifoliate) was found in China (Wu et al., 2004). Creation of citrus periclinal chimeras has been developed as a potential breeding method to improve disease resistance and fruit quality by combining traits from two cultivars. Japanese scientists created synthetic periclinal chimera composed of 'Fukuhara' sweet orange $(C$. sinensis $)$ and 'Kawano Natsudaidai' (C. natsudaidai) (Kuhara, 1989; Ohtsu and Kuhara, 1994). Later, they reported another periclinal chimera of Satsuma mandarin and 'Hamlin' sweet orange (C. sinensis) (Sugawara et al., 2002).

To understand a chimera's construction, reliable markers to identify both parental cultivars are indispensable; only the markers with polymorphism between the parents can be used for analyzing chimeras. The markers include DNA markers, such as simple sequence repeats (SSRs), biochemical components, and morphology etc. In fact, morphological (Marcotrigiano and Bernatzky, 1995; Szymkowiak and Irish, 1999; Szymkowiak and Sussex, 1992), cytological (Chen et al., 
2006), isozymic (Zhou et al., 2002), RAPD (Sugawara et al., 1995, 2002) and SSR (Franks et al., 2002) markers, and even gene expression patterns (Bae et al., 2000; Fleming et al., 1993; Inagaki et al., 1996) have been used to demonstrate the construction and intercellular interaction of plant chimeras. For example, Satsuma mandarin accumulated $\beta$-cryptoxanthin predominantly in the flavedo and juice sacs in mature fruit. In contrast, mature sweet orange (C. sinensis) accumulated violaxanthin isomers predominantly in fruit. Because $\beta$-cryptoxanthin was detected to a minor in sweet orange cultivars, the difference in $\beta$-cryptoxanthin concentration can be used as a discriminating marker among mandarin, orange, and their hybrids (Kato et al., 2004).

Recently, we discovered a naturally occurring citrus graft chimera during exploitation of citrus bud mutation, which was named as the 'Zaohong' navel orange. Its flesh has a deep orange color with orange skin; it is seedless and matures $\approx 1$ month earlier than other local commerical navel orange cultivars. Its special flesh flavor and maturing time have great potential as an early navel orange cultivar. In the present research, the morphological, cytological, biochemical, and molecular characteristics of this chimera were investigated.

\section{Materials and Methods}

Plant Materials. The chimera plant 'Zaohong' navel orange was obtained from an orchard in Hubei Province during a bud mutation investigation. It arose at the junction where a 'Robertson' navel orange bud was top-worked onto Satsuma mandarin in 1980s. Two branches were later observed to produce fruit with rind like the 'Robertson' navel orange but with flesh like the Satsuma mandarin (Fig. 1). Later, the buds from the branches were propagated on a trifoliate orange for evaluating the stability of its traits. All samples, including the fruit and leaves, were from the propagated tress (designated as $\mathrm{V}_{1}$ ). The $\mathrm{V}_{1}$ trees of ' $\mathrm{Zao}$ hong' navel orange and its donor plants, 'Robertson' navel orange and Satsuma mandarin, were maintained at the same orchard. Unfortunately, there were $>10$ clones of Satsuma mandarin grown in this area in 1980s, and it was unclear which was the original top-worked one, so we used 'Guoqing No. 1', a clone of Satsuma mandarin that was a dominant clone in this area at that time, as the donor for genetic study.

Morphological analysis. The leaf length and width of 20 leaves and the fruit width and height of both the chimera and donor plants were measured. Fully developed leaves were collected, and the epidermis was excised and placed on a microscope slide. The lengths of 20 stomatal guard cells and the stomatal density were determined by the
MEASURE function in Image-Pro 3DS 5.1 software (Media Cybernetics, Silver Spring, Md.) according to Kadota and Niimi (2002). For analysis of the leaf transversal section, fully expanded leaves were cut into $0.3 \times 1-\mathrm{cm}$ pieces, dehydrated using graded ethanol solutions $(50 \%, 70 \%, 95 \%$, and 100\%), and embedded in Technovit 7100 resin (Heraeus, Kulzer, Germany). Transversal sections $\approx 1 \mu \mathrm{m}$ thick were cut from the embedded blocks using a Leica Ultracut ultramicrotome (Leica, Bensheim, Germany) and then observed under a light microscope.

Determination OF TOTAL SOLUble SOlids (TSS), TITRATABle ACIDITY (TA), AND TSS:TA RATIO. TSS, TA, and TSS:TA ratio were measured during the fruit ripening. Fruit were sampled every $10 \mathrm{~d}$ from 22 Sept. to 22 Nov. Samples of each cultivar consisted of 10 fruit from 4 trees each time. TSS in fruit juice of each cultivar were determined by a hand-type refractometer (Optics Factory, Chengdu, China). Total TA was determined using an acid-base titration method. Fruit juice $(5 \mathrm{~mL})$ and distilled water $(100 \mathrm{~mL})$ were added in a conical flask and titrated with aqueous $\mathrm{NaOH}(0.1 \mathrm{~N})$ to an endpoint of $\mathrm{pH} 8.1$.

Flow-CYTOMETRIC AnALYSis. The ploidy level of 'Zaohong' was determined by flow cytometry according to Xu et al. (2004) with minor modifications. About $1 \mathrm{~cm}^{2}$ of leaf was chopped with a sharp razor blade, in a 55-mm-diameter plastic petri dish containing HR-A nuclei extraction solution (Partec highresolution staining kit; Partec $\mathrm{GmbH}$, Münster, Germany) and then filtered through a 50- $\mu \mathrm{m}$ Celltrics (Partec $\mathrm{GmbH}$, Münster, Germany) disposable filter. The suspension of released nuclei was stained with HR-B DAPI staining solution (Partec

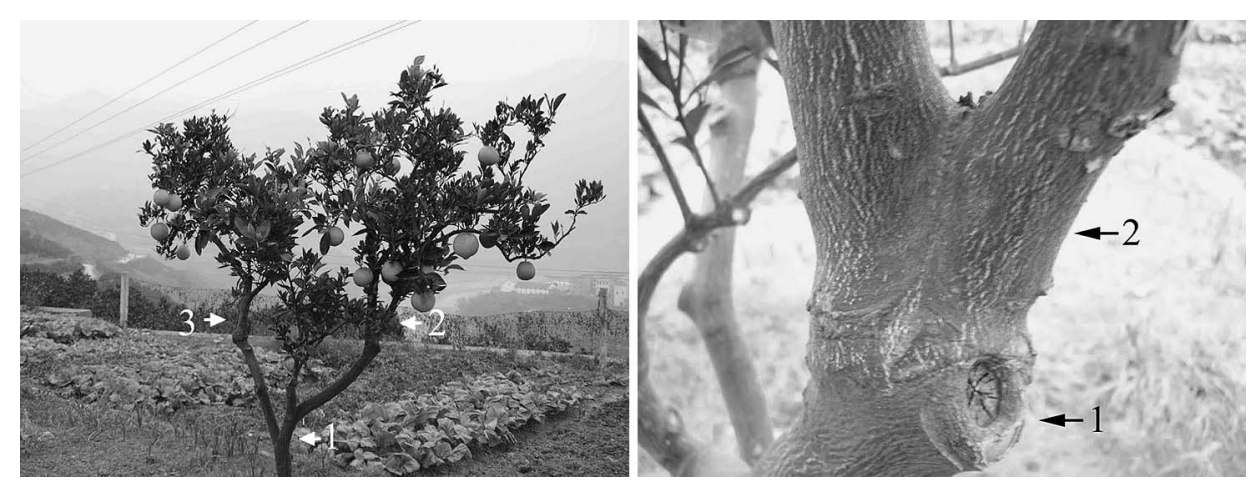

Fig. 1. Original chimeral tree of 'Zaohong' navel orange: (1) Satsuma mandarin, (2) 'Zaohong' navel orange, (3) 'Robertson' navel orange.

Table 1. Leaf morphological characters of 'Zaohong' navel orange and its donor plants.

\begin{tabular}{lccc}
\hline Characteristic & $\begin{array}{c}\text { 'Guoqing No. 1' Satsuma } \\
\text { mandarin }\end{array}$ & $\begin{array}{c}\text { 'Zaohong' navel } \\
\text { orange }\end{array}$ & $\begin{array}{c}\text { 'Robertson' navel } \\
\text { orange }\end{array}$ \\
\hline Leaf length $(\mathrm{cm})$ & $10.6 \pm 0.89 \mathrm{a}^{\mathrm{z}}$ & $8.26 \pm 1.28 \mathrm{~b}$ & $7.84 \pm 0.92 \mathrm{~b}$ \\
Leaf width $(\mathrm{cm})$ & $3.98 \pm 0.44 \mathrm{a}$ & $3.91 \pm 0.79 \mathrm{a}$ & $3.54 \pm 0.52 \mathrm{a}$ \\
Leaf index & $2.67 \pm 0.25 \mathrm{a}$ & $2.19 \pm 0.29 \mathrm{~b}$ & $2.23 \pm 0.19 \mathrm{~b}$ \\
$\quad$ & & & \\
$\quad$ (length/width) & $19.25 \pm 2.82 \mathrm{~b}$ & $20.63 \pm 2.80 \mathrm{~b}$ & $26.20 \pm 2.18 \mathrm{a}$ \\
Stoma length $(\mu \mathrm{m})$ & $585.60 \pm 95.78 \mathrm{c}$ & $768.00 \pm 85.87 \mathrm{~b}$ & $854.4 \pm 83.77 \mathrm{a}$ \\
$\quad\left(\right.$ no. $\left./ \mathrm{mm}^{2}\right)$ & & &
\end{tabular}

${ }^{\mathrm{z}}$ Means within a line followed by different letters are significantly different at $P<0.01$ according to least-significance difference test. 


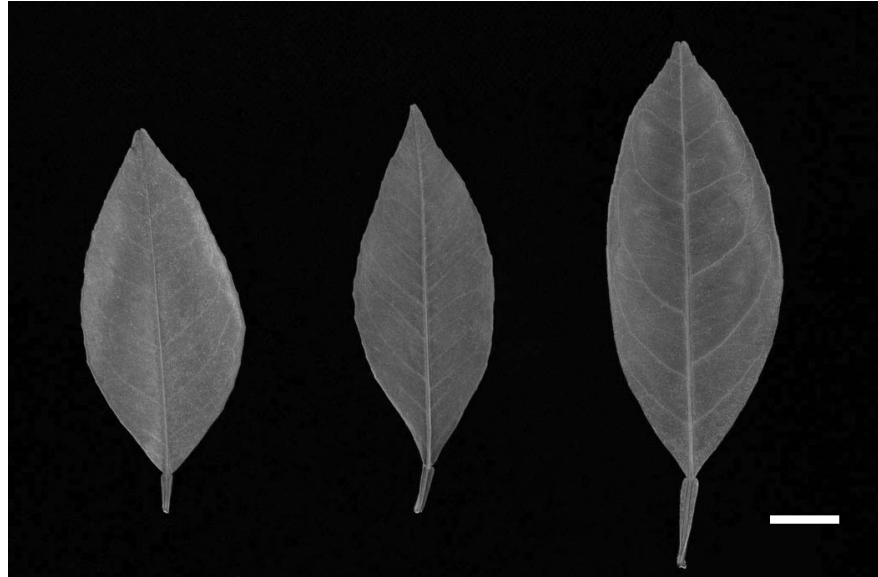

Fig. 2. Leaf morphology of 'Zaohong' navel orange and its donor plants. From left to right: 'Robertson' navel orange, 'Zaohong' navel orange, 'Guoqing No. 1' Satsuma mandarin $(\mathrm{bar}=1.5 \mathrm{~cm})$.
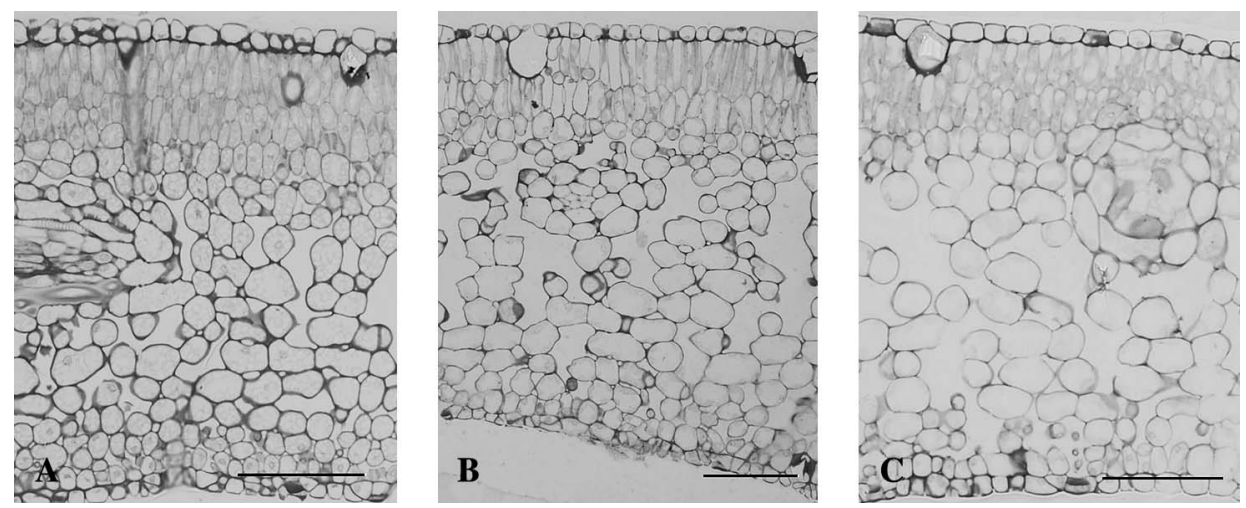

Fig. 3. Leaf transversal sections of (B) 'Zaohong' navel orange and its donors: (A) 'Guoqing No. 1' Satsuma mandarin and $(\mathbf{C})$ 'Robertson' navel orange $($ bar $=80 \mu \mathrm{m})$.
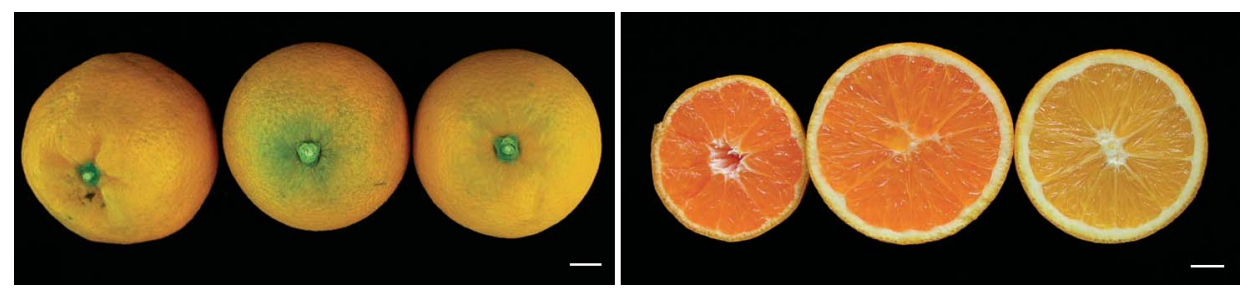

Fig. 4. Fruit morphology of 'Zaohong' navel orange and its donor plants. From left to right: 'Guoqing No. 1' Satsuma mandarin, 'Zaohong' navel orange, 'Robertson' navel orange $(\mathrm{bar}=1.5 \mathrm{~cm})$.

Table 2. Fruit morphological characters of 'Zaohong' navel orange and its donor plants.

\begin{tabular}{lccc}
\hline Characteristic & $\begin{array}{c}\text { 'Guoqing No. 1' } \\
\text { Satsuma mandarin }\end{array}$ & $\begin{array}{c}\text { 'Zaohong' } \\
\text { navel orange }\end{array}$ & $\begin{array}{c}\text { 'Robertson' } \\
\text { navel orange }\end{array}$ \\
\hline Width $(\mathrm{cm})$ & $6.48 \pm 0.25 \mathrm{~b}^{\mathrm{y}}$ & $6.87 \pm 0.25 \mathrm{~b}$ & $8.22 \pm 0.37 \mathrm{a}$ \\
Height $(\mathrm{cm})$ & $5.10 \pm 0.29 \mathrm{c}$ & $6.52 \pm 0.24 \mathrm{~b}$ & $8.22 \pm 0.51 \mathrm{a}$ \\
$\begin{array}{l}\text { Fruit index } \\
\quad(\text { height/width) }\end{array}$ & $0.79 \pm 0.04 \mathrm{~b}$ & $0.95 \pm 0.03 \mathrm{a}$ & $1.00 \pm 0.02 \mathrm{a}$ \\
Shape & Oblate & Spheroid & Spheroid \\
Color of juice sac & Orange & Orange & Yellow \\
Aroma of rind & Weak & Strong & Strong
\end{tabular}

${ }^{\mathrm{y}}$ Means within a line followed by different letters are significantly different at $P<0.01$ according to least-significance difference test. high-resolution staining kit). Finally, the samples were analyzed with a Partec ploidy analyzer. To determine the standard ak of diploid cells (2C DNA), at least 10 leaves were collected (Ded about channel 50 of relative fluorescent intensity. ANALYSIS. The total DNA of the leaves of 'Zaohong' navel orange and its donor plants was extracted according to the method of Cheng et al. (2003b). SSR and cpSSR analysis was conducted according to the procedure of Cheng et al. (2003a, 5) with minor modifications. About $100 \mathrm{ng}$ of genomic $.4 \mathrm{~mm}$ dNTPs, $1.5 \mathrm{~mm} \mathrm{MgCl}_{2}, 0.5$ U Taq DNA polyin a total reaction volume of $20 \mu \mathrm{L}$. The at $94{ }^{\circ} \mathrm{C}$ for $3 \mathrm{~min} ; 32$ cycles of $1 \mathrm{~min}$ (denaturing) at $94{ }^{\circ} \mathrm{C}, 40 \mathrm{~s}$ (annealing) at $55^{\circ} \mathrm{C}, 2 \mathrm{~min}$ (elongation) at $72{ }^{\circ} \mathrm{C}$; and one final cycle of $10 \mathrm{~min}$ at $72{ }^{\circ} \mathrm{C}$, after which the samples were stored at $4{ }^{\circ} \mathrm{C}$. The products were analyzed on $6.0 \%(\mathrm{w} / \mathrm{v})$ denaturing polyacrylamide gels, and the gels were silver-stained according to the manufacturers' protocol for use of Silver Sequence DNA staining reagents (Promega, Madison, Wis.). Primers used for SSR analysis were based on those of Kijas et al. (1997). Analysis of cpSSR was performed with primers (SPCC1, SPCC3, SPCC9, SPCC11) synthesized as reported by Cheng et al. (2005).

\section{HPLC analysis}

Carotenoid Quantification in CITRUS FRUIT. Quantification of carotenoids was conducted according to Lee et al. (2001) with modification. Samples were homogenized to powder in liquid nitrogen and freezedried; $2 \mathrm{~g}$ of freeze-dried powder was extracted with $20 \mathrm{~mL}$ of extracting solvent (50 hexane : 25 acetone : 25 ethanol) containing 10\% (w/v) basic magnesium carbonate in an ultrasonic cleaner (Fisher Scientific, Pittsburgh, $\mathrm{Pa}$.) for $30 \mathrm{~min}$, and centrifuged for $5 \mathrm{~min}$ at $3000 g_{\mathrm{n}}$ at $4{ }^{\circ} \mathrm{C}$ (Beckman Coulter, Palo Alto, Calif.). The top layer of hexane containing the color was recovered and transferred to a $25-\mathrm{mL}$ volumetric flask. The volume of recovered hexane was then adjusted to $25 \mathrm{~mL}$ with hexane. Saponification was carried out overnight using an aqueous $20 \%$ methanolic $\mathrm{KOH}$ solution in the dark at room temperature. The experiment was conducted under dimmed light, and all samples were wrapped in foil. 

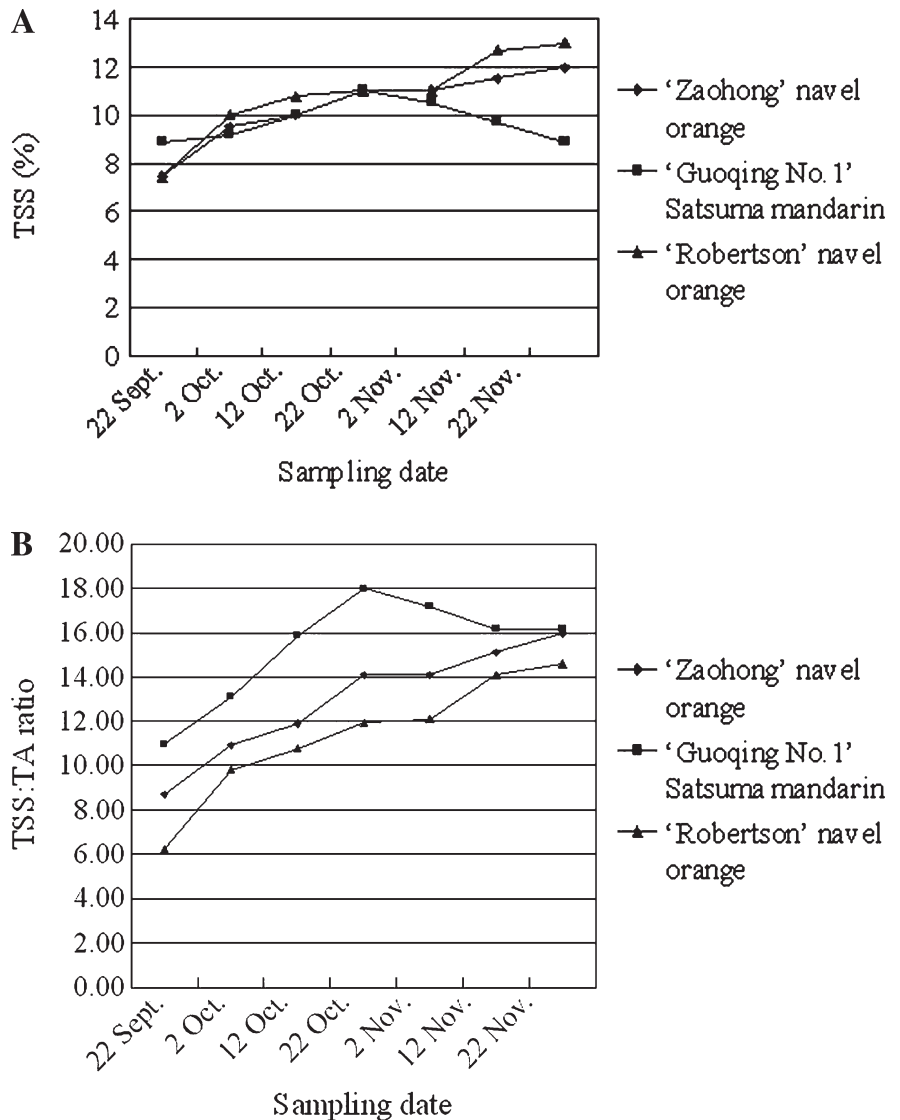

Fig. 5. Changes in (A) total soluble solids [TSS (\%)] and (B) TSS:titratable acidity (TA) ratio during fruit ripening of 'Zaohong' navel orange and its donor plants.

HPLC ANALYSIS OF CAROTENOIDS. Carotenoid pigments were analyzed by RP-HPLC using the binary gradient elution procedure with modification from Lee et al. (2001). Chromatography was carried out with a Waters Corp. (Milford, Mass.) liquid chromatography system equipped with a model $600 \mathrm{E}$ solvent delivery system, a model 2996 photo diode array detection (DAD) system, a model 717 plus autosampler, and an Empower chromatography manager (Waters Corp.). $\mathrm{A}_{30}$ carotenoid column $(150 \times 4.6 \mathrm{~mm}$ i.d., $3 \mu \mathrm{m})$ from YMC (Waters Corp.) was used with $81 \mathrm{MeOH}: 15 \mathrm{MTBE}: 4 \mathrm{H}_{2} \mathrm{O}$ (by volume, eluent $\mathrm{A}$ ), $6 \mathrm{MeOH}: 90$ MTBE : $4 \mathrm{H}_{2} \mathrm{O}$ (by volume, eluent B) as mobile phases. The eluent contained $0.01 \%$ BHT to prevent degradation of carotenoids on the column. The flow rate was 1 $\mathrm{mL} \cdot \mathrm{min}^{-1}$, with the column temperature set at $30^{\circ} \mathrm{C}$, and the injection

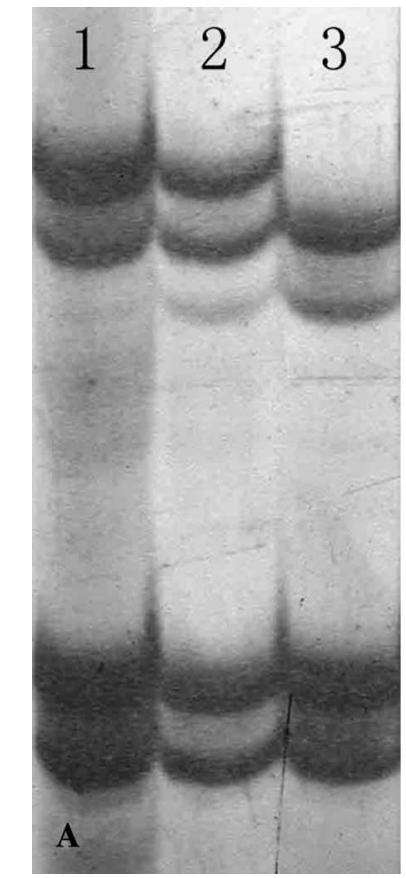

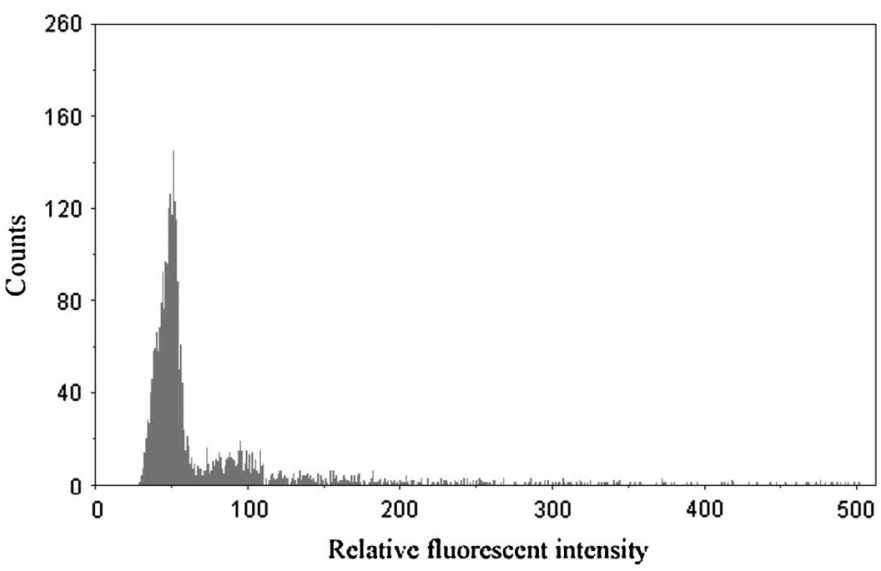

Fig. 6. Ploidy analysis of 'Zaohong' navel orange and its donor plants (three samples were run together).

volume was $40 \mu \mathrm{L}$. A linear gradient program was performed as follows: $100 \%$ A to $100 \%$ B in 90 min and then back to the initial condition for re-equilibration. Analysis was conducted under subdued light to avoid carotenoid degradation during analysis.

Violaxanthin and $\beta$-cryptoxanthin standards were obtained from CaroteNature (Lupsingen, Switzerland).

\section{Results}

LEAF MORPHOLOGY. 'Robertson' navel orange and Satsuma mandarin were different in leaf morphology except leaf width (Table 1, Fig. 2). The leaf index of the 'Zaohong' navel orange was similar to that of its inner tissue donor plant, the 'Robertson' navel orange; this is consistent with the report that the $\mathrm{L}_{2}$ lineage has a major influence on leaf shape
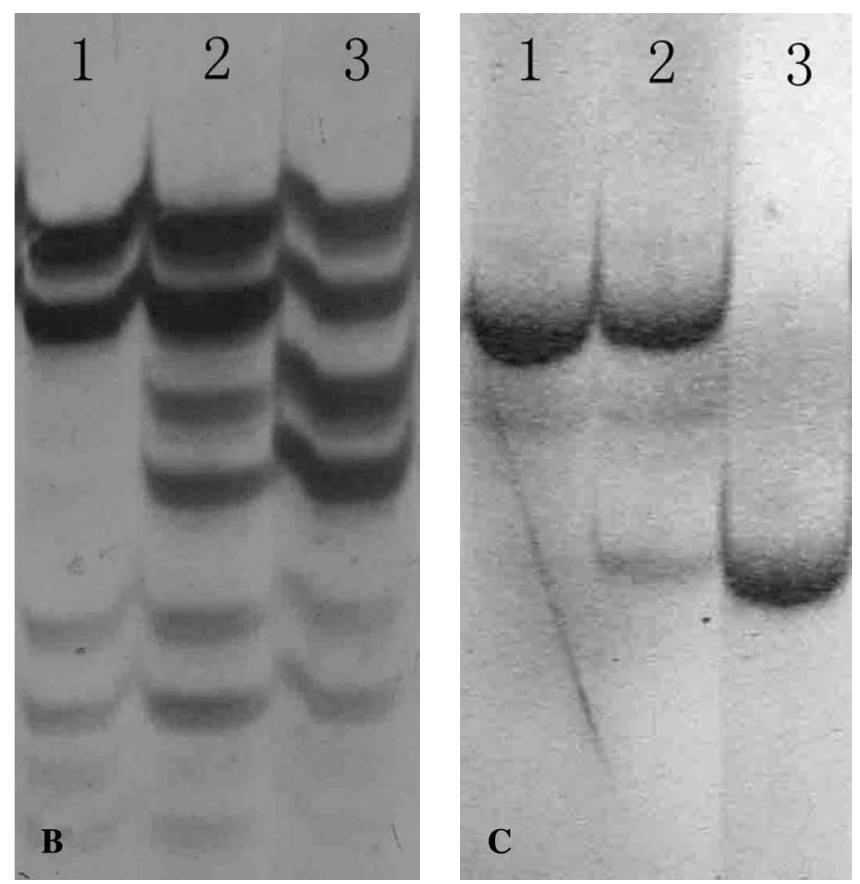

Fig. 7. SSR analysis of 'Zaohong' navel orange and its donor plants, primers TAA15 (A), TAA27 (B) for nuclear genome and primer SPCC1 (C) for chloroplast genome: lanes 1, 'Robertson' navel orange; lanes 2, 'Zaohong' navel orange; lanes 3, 'Guoqing No. 1' Satsuma mandarin. 

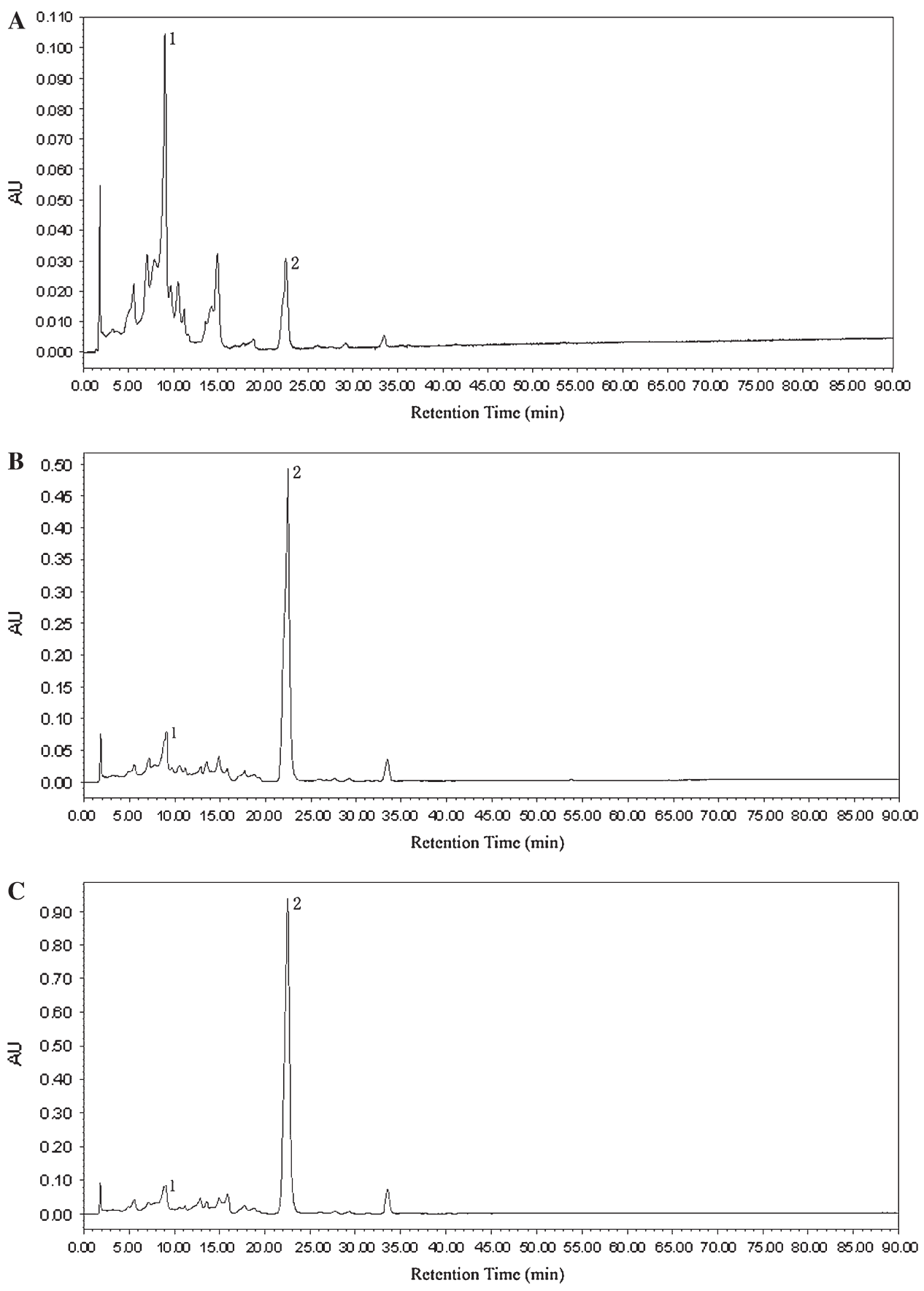

Fig. 8. HPLC chromatogram for carotenoid in the flesh of (B) 'Zaohong' navel orange and its donors: (A) 'Robertson' navel orange and (C) 'Guoqing No. 1' Satsuma mandarin (peak 1, cis-violaxanthin; peak 2, $\beta$-cryptoxanthin; $\mathrm{AU}=$ absorbance units).

in dicots (Dolan and Poething, 1998; Zhou et al., 2002). Transversal sections of mature leaves revealed that both 'Zaohong' and 'Robertson' navel oranges had well-organized cell layering with one layer of epidermis encasing two layers of upper palisade parenchyma, while Satsuma mandarin had a mixed cell layering with three layers of palisade parenchyma present in the same leaf blade tissue (Fig. 3). Significant differences in the length and density of the stomata were observed between Satsuma mandarin and 'Robertson' navel orange; however, the stoma length of 'Zaohong' navel orange was similar to that of Satsuma mandarin (Table 1).
Fruit Characteristics. Photographs of fruit of the chimeras and donor plants are shown in Fig. 4. Morphological characteristics are summarized in Table 2.

'Robertson' navel orange had large spheroid fruit of $8.22 \mathrm{~cm}$ diameter, $8.22 \mathrm{~cm}$ high, and had yellow juice sacs. The aroma of its rind was strong. The rind was $0.70 \mathrm{~cm}$ thick. The albedo tissues were thick and difficult to peel. All fruit had navels. Satsuma mandarin had small oblate fruit of $6.48 \mathrm{~cm}$ diameter, $5.10 \mathrm{~cm}$ high, and had orange juice sacs. The aroma of its rind was weaker than that of 'Robertson' navel orange, and the rind was $\approx 0.40 \mathrm{~cm}$ thick. The albedo tissues were very thin and easy to peel. There was no navel in the top of the fruit. 'Zaohong' navel orange had middle spheroid fruit of $6.87 \mathrm{~cm}$ diameter, $6.52 \mathrm{~cm}$ high, and had orange juice sacs. Its rind was $\approx 0.60 \mathrm{~cm}$ thick, the aroma of which was strong. The albedo tissues were thicker than in the Satsuma mandarin but thinner than in the 'Robertson' navel orange. It was easier to peel than the 'Robertson' navel orange but more difficult than the Satsuma mandarin. All fruit had navels. This observation was consistent with the conclusions that juice sacs originated from the $\mathrm{L}_{1}$ layer and that $\mathrm{L}_{2}$ or $\mathrm{L}_{3}$ determined the fruit shape (Cameron et al., 1964; Zhou et al., 2002).

INTERNAL FRUIT QUALITY. Internal quality is important for determining the value of new citrus cultivars. TSS, TA, and TSS:TA ratio are important factors for evaluating fruit quality. As shown in Fig. 5, in early October the TSS:TA of 'Zaohong' navel orange was $>10$; on 22 Oct., its TSS reached $11.0 \%$, similar to that of 'Guoqing No. 1' Satsuma mandarin and 'Robertson' navel orange. However, at this stage, the TSS:TA ratio of 'Zaohong' navel orange was 14.10, significantly higher than 11.96 of 'Robertson' navel orange. In this area, the TSS:TA ratio of 'Robertson' navel orange cannot reach 14 until the middle of November, when the navel orange harvest begins. This means that the 'Zaohong' navel orange reaches its mature stage $\approx 1$ month earlier than 'Robertson' navel orange, which was the earliest when compared with other navel orange cultivars - including 'Fukumoto', 'Newhall', 'Robertson', and 'Seike' - grown in the same area.

Ploidy Determination. Flow cytometry was used to analyze the ploidy levels of 'Zaohong' navel orange and its donor plants. When compared with the diploid control, 'Robertson' 
Table 3. Spectroscopic characteristics of carotenoid pigments found in the flesh of 'Zaohong' navel orange and its donors.

\begin{tabular}{|c|c|c|c|c|c|}
\hline $\begin{array}{l}\text { Peak } \\
\text { no. }\end{array}$ & $\begin{array}{l}\text { Retention } \\
\text { time } \\
(\mathrm{min})\end{array}$ & $\begin{array}{l}\text { Absorption } \\
\text { maxima } \\
(\mathrm{nm})\end{array}$ & $\% \mathrm{III} / \mathrm{II}$ & $\% \mathrm{III} / \mathrm{II}^{\mathrm{x}}$ & Carotenoid \\
\hline 1 & 9.2 & $\begin{array}{c}412.9,435.8 \\
464.9\end{array}$ & 94 & $94^{\mathrm{x}}$ & cis-Violaxanthin \\
\hline 2 & 22.7 & $\begin{array}{c}429.5,451.5 \\
479.4\end{array}$ & 39 & $40^{\mathrm{x}}$ & $\beta$-Cryptoxanthin \\
\hline
\end{tabular}

${ }^{\mathrm{x}}$ Values obtained from standards.

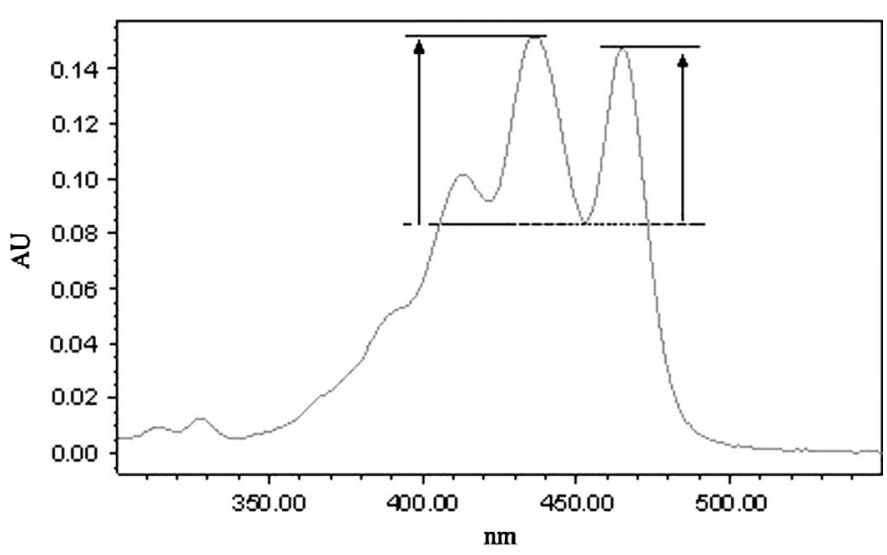

Fig. 9. Spectral fine structure of violaxanthin (AU, absorbance units).

navel orange, and Satsuma mandarin, their fluorescence intensities were present to 50 , the 'Zaohong' navel orange demonstrated a fluorescence intensity similar to the control, indicating its diploid nature (Fig. 6).

NuClear GeNOME COMPOSITION. To determine the nuclear composition, SSR analysis was performed between 'Zaohong' navel orange and its donor plants. Two out of the five tested SSR primers-TAA15 and TAA27-revealed polymorphisms between $C$. sinensis and C. unshiu. The amplified products of these polymorphic primers showed that the band patterns of 'Zaohong' navel orange contain bands from both 'Robertson' navel orange and Satsuma mandarin (Fig. 7A and B), which indicated that 'Zaohong' navel orange contained nuclear genomes from these two donors.

Chloroplast genome composition. For the chloroplast genome, 'Zaohong' navel orange was characterized using four pairs of cpSSR primers (SPCC1, SPCC3, SPCC9, and SPCC11), which were polymorphic between 'Robertson' navel orange and Satsuma mandarin. 'Zaohong' shared combined band patterns from 'Robertson' navel orange and Satsuma mandarin, suggesting that it harbored chloroplast genomes from both donor plants (Fig. 7C).

IDENTIFICATION OF CAROTENOIDS. Peaks 1 and 2 in Fig. 8 were identified as cis-violaxanthin and $\beta$-cryptoxanthin, respectively, by comparing their absorption spectra and retention times with those of commercially available authentic standards (Table 3 ). The ratio of peak heights has proven useful to compare the spectra fine structure, as described by Britton (1995). A numerical notation (\%III/II), which describes the ratio of the peak height of the longest wavelength absorption band (band III) to that of the middle absorption band (band II) as a percentage, was also used for identification (Fig. 9). Values (\%III/II) obtained from this study agreed well with the values from standards. Table 3 showed the chromatographic retention of carotenoids and spectral characteristics obtained by authentic standards. Mature 'Robertson' navel orange predominantly accumulated violaxanthin isomers in the flesh. Violaxanthin is a yellow pigment with the main cis-form in citrus, having visible absorption maxima of 413, 436, and $465 \mathrm{~nm}$, while the pigment with the highest concentration in Satsuma mandarin was $\beta$-cryptoxanthin. It is an orange carotenoid with visible absorption maxima of 479, 452, and $429 \mathrm{~nm}$. Both 'Zaohong' navel orange and Satsuma mandarin accumulated $\beta$-cryptoxanthin predominantly in the juice sacs in the mature fruit. This observation was consistent with the suggestion that juice sacs were originated from the $\mathrm{L}_{1}$ layer (Zhou et al., 2002).

\section{Discussion}

The 'Zaohong' navel orange is a naturally occurring periclinal chimera that consists of $\mathrm{L}_{1}$ from Satsuma mandarin and $\mathrm{L}_{2} / \mathrm{L}_{3}$ from 'Robertson' navel orange. Its characteristics have been stable in $V_{1}$ plants for several years. Its fruit flesh has the mixed flavor and texture from both Satsuma mandarin and 'Robertson' navel orange, and it is easy to peel. The flesh is orange in color, fine, crisp, tender, and very juicy with an orange's aroma. The whole fruit has a pleasing aroma and excellent shelf life, as does the 'Robertson' navel orange. Thus, the 'Zaohong' navel orange combines valuable traits of its donor plants. It matures in the middle of October, which is $\approx 1$ month earlier than other cultivated navel orange cultivars in the same area. To our knowledge, it is the earliest-maturing navel orange, and it will have good potential for the fresh fruits market.

Intercellular morphogenetic and physiological interactions and cell displacement have been observed in chimeric plants (Szymkowiak and Irish 1999; Zhou et al., 2002). The observations of stomata density and flesh aroma in this study indicated that chimeric cells likely were derived from both parental cultivars. Further studies are required to reveal the interaction between cells of 'Robertson' navel orange and Satsuma mandarin in the chimera 'Zaohong' navel orange.

\section{Literature Cited}

Asins, M.J., A.J. Monforte, P.F. Mestre, and E.A. Carbonell. 1999. Citrus and Prunus copia-like retrotransposons. Theor. Appl. Genet. 99:503-510.

Bae, C.H., T. Abe, N. Nagata, N. Fukunishi, T. Matsuyama, T. Nakano, and S. Yoshida. 2000. Characterization of a periclinal chimera variegated tobacco (Nicotiana tabacum L.). Plant Sci. 151:93-101.

Britton, G. 1995. Spectroscopy, p. 13. In: G. Britton, S. Liaaen-Jensen, and H. Pfander (eds.). Carotenoids, Vol. 1B. Birkhauser, Boston.

Burge, G., E. Morgan, and J. Seelye. 2002. Opportunities for synthetic plant chimeral breeding: past and future. Plant Cell Tissue Organ Cult. 70:13-21.

Cameron, J., R. Soost, and E. Olson. 1964. Chimeric basis for color in pink and red grapefruit. J. Hered. 55:23-28.

Chen, L.P., Y.M. Ge, and X.Y. Zhu. 2006. Artificial synthesis of interspecific chimeras between tuber mustard (Brassica juncea) and cabbage (Brassica oleracea) and cytological analysis. Plant Cell Rpt. 25:907-913. 
Cheng, Y.J., M. Carmen, H.J. Meng, W.W. Guo, N.G. Tao, and X.X Deng. 2005. A set of primers for analyzing chloroplast DNA diversity in Citrus and related genera. Tree Physiol. 25:661-672.

Cheng, Y.J., W.W. Guo, and X.X. Deng. 2003a. cpSSR: a new tool to analyze chloroplast genome of Citrus somatic hybrids. Acta Bot. Sin. 45(8):906-909.

Cheng, Y.J., W.W. Guo, H.L. Yi, X.M. Pang, and X.X. Deng. 2003b. An efficient protocol for genomic DNA extraction from citrus species. Plant Mol. Biol. Rpt. 21:177a-177g.

Dolan, L. and R. Poething. 1998. The okra leaf shape mutation in cotton is active in all cell layers of the leaf. Amer. J. Bot. 85:322-327.

Doring, H.P., J.X. Lin, H. Uhrig, and F. Salamini. 1999. Clonal analysis of the development of the barley (Hordeum vulgare L.) leaf using periclinal chlorophyll chimeras. Planta 207:335-342.

Fleming, A.J., T. Mandel, I. Roth, and C. Kuhlemeier. 1993. The patterns of gene expression in the tomato shoot apical meristem. Plant Cell 5:297-309.

Franks, T., R. Botta, and M.R. Thomas. 2002. Chimerism in grapevines: implications for cultivar identity, ancestry and genetic improvement. Theor. Appl. Genet. 104:192-199.

Frost, H.B. and C.A. Krug. 1942. Diploid-tetraploid periclinal chimeras as bud variants in citrus. Genetics 27:619-634.

Inagaki, Y., Y. Hisatomi, and S. Iida. 1996. Somatic mutations caused by excision of the transposable element, Tpn1, from the $D F R$ gene for pigmentation in sub-epidermal layer of periclinally chimeric flowers of Japanese morning glory and their germinal transmission to their progeny. Theor. Appl. Genet. 92:499-504.

Kadota, M. and Y. Niimi. 2002. In vitro induction of tetraploid plants from a diploid Japanese pear cultivar (Pyrus pyrifolia N. cv. Hosui). Plant Cell Rpt. 21:282-286.

Kato, M., Y. Ikoma, H. Matsumoto, M. Sugiura, H. Hyodo, and M. Yano. 2004. Accumulation of carotenoids and expression of carotenoid biosynthetic genes during maturation in Citrus fruit. Plant Physiol. 134:824-837.

Kijas, J., M. Thomas, J. Fowler, and M. Roose. 1997. Integration of trinucleotide microsatellite into a linkage map of citrus. Theor. Appl. Genet. 94:701-708.

Kuhara, S. 1989. Artificial production of citrus periclinal chimera and disease resistance of these plants. Shokubutsu Bochi 43:25-29.

Lee, H.S., W.S. Castle, and G.A. Coates. 2001. High-performance liquid chromatography for the characterization of carotenoids in the new sweet orange (Early gold) grown in Florida, USA. J. Chromatogr. A 913:371-377.

Marcotrigiano, M. and R. Bernatzky. 1995. Arrangement of cell layers in the shoot apical meristems of periclinal chimeras influences cell fate. Plant J. 7(2):193-202.

Ohtsu, Y. and S. Kuhara. 1994. Periclinal chimera of citrus resistant to citrus canker and citrus tristeza virus: chimerism and composition of fruit tissue in the synthetic periclinal chimeras ' $\mathrm{FN}-1$ ' and ' $\mathrm{FN}-3$ '. Ann. Phytopathol. Soc. Jpn. 60:20-26.

Schmidt, A. 1924. Histologische Studien an phanerogamen Vegetationspunkten. Bot. Arch. 8:345-404.

Shen, D.X., Y.Y. Wang, and L.G. Cheng. 1998. Citrus genetics and breeding. Scientific Publishers, Beijing, China (in Chinese).

Spiegel-Roy, P. and E. Goldschmidt. 1996. Biology of citrus. Cambridge University Press, Cambridge, U.K.

Sugawara, K., A. Oowada, T. Moriguchi, and M. Omura. 1995. Identification of Citrus chimeras by RAPD markers. HortScience 30(6):1276-1278.

Sugawara, K., T. Wakizuka, A. Oowada, T. Moriguchi, and M. Omura. 2002. Histogenic identification by RAPD analysis of leaves and fruit of newly synthesized chimeric Citrus. J. Amer. Soc. Hort. Sci. 127(1):104-107.

Szymkowiak, E. and E. Irish. 1999. Interactions between jointless and wild-type tomato tissues during development of the pedicel abscission zone and the inflorescence meristem. Plant Cell 11: 159-176.

Szymkowiak, E. and I. Sussex. 1992. The internal meristem layer $\left(\mathrm{L}_{3}\right)$ determines floral meristem size and carpel number in tomato periclinal chimeras. Plant Cell 4:1089-1100.

Tanaka, Y. 1980. An iconograph of Japanese citrus fruits: a monographic study of species and varieties of citrus fruits grown in Japan, Vol. 3. Yokendo, Tokyo.

Wu, H.M., B.M. Lin, Z.X. Lai, L.X. Lu, G.F. Lin, D.M. Pan, and J.F. Yang. 2004. An intergeneric grafting chimera name: + Citroponcirus Hormish. J. Trop. Subtrop. Bot. 12(2):177-181 (in Chinese).

Xu, X.Y., J.H. Liu, and X.X. Deng. 2004. Production and characterization of intergeneric diploid cybrids derived from symmetric fusion between Microcitrus papuana Swingle and sour orange (Citrus aurantium). Euphytica 136:115-123.

Zhou, J.M., Y. Hirata, I.S. Nou, H. Shiotani, and T. Ito. 2002. Interactions between different genotypic tissues in citrus graft chimeras. Euphytica 126:355-364. 